\title{
Monitoring of Lipids, Enzymes, and Creatine Kinase in Patients on Lipid-Lowering Drug Therapy
}

\author{
Olov Wiklund • Carlo Pirazzi • Stefano Romeo
}

Published online: 26 July 2013

(C) The Author(s) 2013. This article is published with open access at Springerlink.com

\begin{abstract}
A number of plasma lipid parameters have been used to estimate cardiovascular risk and to be targets for treatment to reduce risk. Most risk algorithms are based on total cholesterol (T-C) or low-density lipoprotein cholesterol (LDLC) and high-density lipoprotein cholesterol (HDL-C), and most intervention trials have targeted the LDL-C levels. Emerging measures, which in some cases may be better for risk calculation and as alternative treatment targets, are apolipoprotein B and non-HDL-C. Other lipid measures that may contribute in risk analysis are triglycerides (TG), lipoprotein(a), and lipoprotein-associated phospholipase $\mathrm{A}_{2}$. The primary treatment target in cardiovascular prevention is LDL-C, and potential alternative targets are apoB and non-HDL-C. In selected individuals at high cardiovascular (CV) risk, TG should be targeted, but HDL-C, Lp(a), and ratios such as LDL-C/HDL-C or apoB/apoAI are not recommended as treatment targets. Lipids should be monitored during titration to targets. Thereafter, lipids should be checked at least once a year or more frequently to improve treatment adherence if indicated. Monitoring of muscle and liver enzymes should be done before the start of treatment. In stable conditions during treatment, the focus should be on clinical symptoms that may alert muscle or liver complications. Routine measurement of CK or ALT is not necessary during treatment with statins.
\end{abstract}

Keywords Dyslipidemia $\cdot$ Cardiovascular prevention . Statin $\cdot$ Lipoprotein $\cdot$ Myalgia $\cdot$ Treatment $\cdot$ Lipids . Enzymes $\cdot$ Creatine kinase $\cdot$ Lipid-lowering drug therapy

This article is part of the Topical Collection on Lipid Abnormalities and Cardiovascular Prevention

O. Wiklund $(\bowtie) \cdot$ C. Pirazzi $\cdot$ S. Romeo

Wallenberg Laboratory, Department of Experimental and Clinical

Medicine, Sahlgrenska Academy at the University of Gothenburg,

Sahlgrenska University Hospital, 41345 Göteborg, Sweden

e-mail: Wiklund@wlab.gu.se

\section{Introduction}

An overwhelming number of studies in the past decades have established dyslipidemia as the major risk factor for the development of atherosclerotic cardiovascular disease. Recent reductions in plasma cholesterol levels have contributed to a dramatic decrease in the incidence of premature coronary heart disease in the western world $[1,2]$. However, atherosclerotic cardiovascular disease remains the main killer in the western world and its impact is increasing worldwide.

Although lifestyle factors, primarily dietary habits, are the fundamental targets for lipid lowering, the development of pharmacological interventions - in particular, statins-has been a major contributor to reduction of disease. Statins are now used by millions of people worldwide and their dramatic effect on cardiovascular disease has been shown in a large number of trials and also in meta-analyses. Based on results from cohort studies the total CV risk can be estimated with risk estimation tools that have been developed for that purpose. Armed with increased knowledge of lipid and lipoprotein metabolism and of the role of lipoproteins in the development of atherosclerosis, it is important to determine which lipid measurements are the most informative in risk estimation and which lipid measures are the best to target for therapy. An active discussion on these subjects has taken place in recent years. Furthermore, recent guidelines suggest more intense lipid lowering in selected patients $[3 \cdot 4,4]$. However, intense lipid lowering increases the risk of side effects from pharmacological treatment and the question on how to monitor safety during treatment has become more important.

In this review, the advantages and disadvantages of the different lipid measures and lipid targets are discussed in relation to the current literature. Safety monitoring is also discussed and updated with regard to recent studies. 


\section{Which Lipid Parameters Should Be Used to Estimate Cardiovascular Risk?}

A first step in cardiovascular prevention is to estimate the risk for cardiovascular disease (CVD) in the individual. Performing a risk analysis is important from several aspects. First, the intervention can be targeted to subjects with high risk. The absolute reduction of $\mathrm{CV}$ events is higher in the high risk patients. Consequently, the cost per prevented event is lower in subjects with high risk. Risk analysis is also an important tool for the design of prevention. Which factors should be treated? Furthermore, the level of target to reach can be adapted to the risk level. Risk analysis will also educate the patient to improve the adherence to treatment. Some patients have an underlying condition associated with high risk, and in these cases no further risk analysis has to be done. This is the case in patients with established CVD, diabetes, chronic kidney disease (CKD), or markedly elevated single risk factor, such as familial hypercholesterolemia. A number of plasma lipid parameters have been used to estimate cardiovascular risk and to be targets for treatment to reduce risk. Most risk algorithms, such as SCORE, Framingham score and Reynolds Risk score, are based on total cholesterol (T-C), or low-density lipoprotein cholesterol (LDL-C) and high-density lipoprotein cholesterol (HDL-C), and most intervention trials have targeted the LDL-C levels. However, a disadvantage of LDL-C is that it does not include the triglyceride-rich atherogenic particles intermediate-density lipoprotein (IDL) and very low-density lipoprotein (VLDL) [5]. These are better described using non-HDL-C (calculated as T-C minus HDL-C) or apolipoprotein B (apoB; the protein component of atherogenic lipoproteins). Because there is only one apoB molecule per lipoprotein particle, apoB concentration is a measure of particle number. Non-HDL-C and apoB have therefore been suggested as alternative or even preferred lipid variables for risk estimation $[6,7]$.

The use of non-HDL-C and apoB may be especially advantageous in patients with combined hyperlipidemia, such as in the metabolic syndrome or type 2 diabetes. Furthermore, LDL-C cannot be calculated with the Friedewald formula [3•] in hypertriglyceridemia ( $\mathrm{TG}>400 \mathrm{mg} / \mathrm{dl}$ or $>4.5 \mathrm{mmol} / \mathrm{L}$ ). A number of studies indicate that apoB is a better predictor than cholesterol measures of cardiovascular risk $[6,7]$, most recently in a meta-analysis of 233,455 subjects and 22,950 events [8]. However, several analyses do not support the conclusion that apoB adds to the information given by the lipid markers including non-HDL-C [9, $10 \bullet \bullet, 11]$. Some studies support non-HDL-C and apoB as better risk indicators in obesity or diabetes $[12,13]$, but 1 study on obesity reports that apolipoproteins do not contribute to risk prediction [11]. The choice between assessments of cholesterol and apolipoproteins for risk analysis seems to be more dependent on practical considerations, such as cost, availability and tradition, than on major differences in risk estimation [9].

Low HDL-C and elevated triglycerides (TG) are both independent risk factors for cardiovascular disease. HDL-C is included in several of the risk algorithms and should always be analyzed to evaluate cardiovascular risk $[3 \cdot 4]$. Although not so strong when corrected for other risk factors, TG also contributes to risk assessment [14]. Furthermore low HDL-C and high TG are ingredients of the dyslipidemia often associated with the metabolic syndrome and type 2 diabetes. HDL-C and TG therefore may indicate the cause of the dyslipidemia and also guide the selection of therapy. Patients with very high TG $(>10 \mathrm{mmol} / \mathrm{L}$ or $>900 \mathrm{mg} / \mathrm{dL})$ should immediately start therapy because of the risk of pancreatitis [15].

The different ratios (apoB/apoAI, T-C/HDL-C, non-HDL$\mathrm{C} / \mathrm{HDL}-\mathrm{C}$ ) give similar information as their components, but may be practical for screening. However, focusing on ratios may hide essential diagnostic information.

New lipid markers for risk estimation have recently emerged, but most of the new variables (such as lipoprotein subclasses and particle size) have yet to prove that they contribute to the total risk estimation above that provided by conventional lipid analyses [16]. In a meta-analysis of 165,544 subjects and 15,126 events, only 2 markers significantly improved the prediction of future cardiovascular events: lipoprotein(a) $(\mathrm{Lp}(\mathrm{a}))$ and lipoprotein-associated phospholipase A2 $\left(\mathrm{LpPLA}_{2}\right)[10 \bullet \cdot$. This is supported by a recent population study from Copenhagen, which suggests that extreme $L p(a)$ levels substantially improves CVD prediction [17]. $\mathrm{Lp}$ (a) has been discussed as a risk factor for decades, and recent data from genetic analyses have shown that $\mathrm{Lp}$ (a) most probably has an etiologic role in atherosclerosis $[18,19]$. $L p(a)$ levels are highly genetically determined and may add information on risk especially in subjects with a family history of cardiovascular disease. Lp-PLA $A_{2}$ also seems to have an etiological role and its potential as a therapeutic target is now being studied in clinical trials $[20,21]$.

\section{Which Lipid Parameters Should be Targeted by Treatment to Reduce Cardiovascular Risk?}

The primary reason to monitor lipids during lipid-lowering treatment should be to evaluate if treatment targets have been reached. Guidelines for target levels of plasma lipids are based on results from randomized controlled trials and from meta-analyses. The absolute target levels still are under debate, but most guidelines have similar approaches in identifying and defining targets $[4,22-26]$ and most identify LDL-C levels as the primary target for treatment. In European guidelines [3•, 4], 
the target of LDL-C is adapted to total CV risk level (Table 1) with a lower level for subjects with very high cardiovascular risk (Table 2). The lower targets suggested in recent guidelines are based on studies comparing different treatment regimens and on meta-analyses of a large number of statin trials [27••, 28]. Although these studies give good support for the low LDL$\mathrm{C}$ targets, the "lower the better" approach is still under debate $[29,30]$. ApoB and non-HDL-C have not been studied as primary targets in randomized studies, but post-hoc analyses suggest that both may be used [31-33] and these analyses form the basis for target levels in guidelines (Table 2).

The concept that more may be achieved with more intense treatment is supported by observations on residual risk during statin treatment. In 1 recent analysis of the JUPITER trial on treatment levels of LDL-C, non-HDL-C, and apoB were found to identify residual risk [34]. Similar observations are reported from the Treating to New Targets (TNT) study [32] and in a recent meta-analysis [33] on association of LDL-C, non-HDL-C and apoB levels with cardiovascular events among patients treated with statins.

Should HDL-C be a target for treatment and monitored during therapy? Recent guidelines do not suggest HDL-C as a treatment target, despite its importance as a marker for future cardiovascular disease [3•, 4]. However, based on epidemiological data, optimal HDL levels are suggested to be $>1.0 \mathrm{mmol} / \mathrm{L}(>40 \mathrm{mg} / \mathrm{dL})$ for men and $>1.2 \mathrm{mmol} / \mathrm{L}($ $>45 \mathrm{mg} / \mathrm{dL}$ ) for women. The potent HDL-elevating drugs cholesteryl ester transfer protein (CETP) inhibitors have not been found to reduce cardiovascular disease; the first CETP inhibitor tested actually showed increased mortality in the treated group, probably due to off-target effects [35], and a study with another CETP inhibitor was prematurely terminated due to lack of effect [36]. Furthermore, genetic studies using mendelian randomization do not support HDL as a direct causative agent for disease [37].

The data supporting TG as a target for drug treatment are less robust than for LDL-C. The optimal TG level is suggested to be below $1.7 \mathrm{mmol} / \mathrm{L}(150 \mathrm{mg} / \mathrm{dL})$, primarily based on epidemiological data [22]. European guidelines suggest that the use of drugs should only be considered if TG is over
$2.3 \mathrm{mmol} / \mathrm{L}(200 \mathrm{mg} / \mathrm{dL})$ and cannot be lowered by life-style changes, and if the subject is at high risk of cardiovascular disease [22].

Levels of $\mathrm{Lp}(\mathrm{a})$ above $30 \mathrm{mg} / \mathrm{dL}$ are associated with increased risk of cardiovascular disease, but there is no evidence at present to show that intervention against high $\mathrm{Lp}$ (a) reduces cardiovascular risk. Thus, no target level for treatment has been recommended $[18,19]$.

\section{Selection of Drugs}

Five main groups of pharmacological agents are, at present, available for the treatment of hyperlipidemia.

\section{Statins}

Statins (HMG-CoA-reductase inhibitors: simvastatin, atorvastatin, pravastatin, rosuvastatin, fluvastatin, lovastatin, and pitavastatin) cause a reduction in intracellular cholesterol levels, leading to increased LDL receptor expression on hepatocyte membranes with a subsequent reduction in the circulating levels of apoB-containing lipoproteins (LDL, IDL, VLDL). A large body of evidence shows that statins are effective in the reduction of LDL-C and cardiovascular events $[27 \bullet \bullet, 28]$, and statins are the first-line treatment for individuals with high levels of LDL-C or combined hyperlipidemia both in primary and secondary prevention. Depending on dose and potency of the statin (rosuvastatin, atorvastatin and pitavastatin being the most potent), a reduction of LDL-C of up to $55 \%$ may be achieved [38]. In patients with moderately elevated TG, statins may reduce TG by about $15 \%$ $20 \%$. A moderate increase in HDL-C $(5 \%-10 \%)$ is also achieved.

\section{Ezetimibe}

Ezetimibe inhibits intestinal and biliary cholesterol absorption, probably via interaction with Niemann-Pick C1-like protein 1 (NPC1L1) [39]. It reduces absorption of dietary

Table 1 Global risk stratification according to the European guidelines on cardiovascular disease prevention in clinical practice (2012)

\begin{tabular}{|c|c|}
\hline Risk level & SCORE (10-year risk of fatal CVD, \%) or risk conditions \\
\hline Low & $<1 \%$ \\
\hline Moderate & $\geq 1 \%$ to $<5 \%$ \\
\hline High & $\begin{array}{l}\geq 5 \% \text { to }<0 \% \text {, or markedly elevated single risk factor (eg, familial dyslipidemia or severe hypertension), or type } 1 \text { or } 2 \text { diabetes } \\
\left.\text { without } \mathrm{CV} \text { risk factors or target organ damage, or moderate CKD (GFR } 30-59 \mathrm{~mL} / \mathrm{min} / 1,73 \mathrm{~m}^{2}\right) \text {. }\end{array}$ \\
\hline Very high & $\begin{array}{l}\geq 10 \% \text {, or documented CVD, or type } 1 \text { or } 2 \text { diabetes with } 1 \text { or more } \mathrm{CV} \text { risk factors and/or organ damage, or severe } \mathrm{CKD}(\mathrm{GFR} \\
\left.<30 \mathrm{~mL} / \mathrm{min} / 1.73 \mathrm{~m}^{2}\right)\end{array}$ \\
\hline
\end{tabular}

(Modified from [4]). 
Table 2 Treatment targets for LDL-C, non-HDL-C, and apoB at different levels of cardiovascular risk

\begin{tabular}{|c|c|c|c|}
\hline \multirow[t]{2}{*}{ Risk level } & \multicolumn{3}{|l|}{ Treatment targets } \\
\hline & LDL-C & Non-HDL-C & ApoB \\
\hline Moderate & $<3.0 \mathrm{mmol} / \mathrm{L}(<115 \mathrm{mg} / \mathrm{dL})$ & $<3.8 \mathrm{mmol} / \mathrm{L}(<145 \mathrm{mg} / \mathrm{dL})$ & \\
\hline High & $<2.5 \mathrm{mmol} / \mathrm{L}(<100 \mathrm{mg} / \mathrm{dL})$ & $<3.3 \mathrm{mmol} / \mathrm{L}(<130 \mathrm{mg} / \mathrm{dL})$ & $<100 \mathrm{mg} / \mathrm{dL}$ \\
\hline \multirow[t]{3}{*}{ Very high } & $<1.8 \mathrm{mmol} / \mathrm{L}(<70 \mathrm{mg} / \mathrm{dL})$ & $<2.6 \mathrm{mmol} / \mathrm{L}(<100 \mathrm{mg} / \mathrm{dL})$ & $<80 \mathrm{mg} / \mathrm{dL}$ \\
\hline & \multicolumn{3}{|c|}{ Desirable level of TG $<1.7 \mathrm{mmol} / \mathrm{L}(<150 \mathrm{mg} / \mathrm{dL})$. } \\
\hline & \multicolumn{3}{|c|}{ Desirable level of HDL-C $>1.0 \mathrm{mmol} / \mathrm{L}(>40 \mathrm{mg} / \mathrm{dL})$ for men, $>1.2 \mathrm{mmol} / \mathrm{L}(>45 \mathrm{mg} / \mathrm{dL})$ for women. } \\
\hline
\end{tabular}

Modified from [61].

and biliary cholesterol as it blocks the enterohepatic circulation, and reduced cholesterol transport to the liver induces increased LDL receptor expression on hepatocytes. Ezetimibe induces a reduction of LDL-C of approximately $15 \%-20 \%$. It is primarily used in combination with a statin with a $22 \%-26 \%$ reduction of LDL-C beyond that obtained by statin alone [40, 41]. Effects on cardiovascular end-points in randomized trials are still lacking, but 1 study, IMPROVEIT, will report in 2013 [42].

\section{Bile Acid Sequestrants}

Bile acid sequestrants (cholestyramine, colestipol, and colesevelam) remove bile acids from the enterohepatic circulation. Because bile acids are synthesized from cholesterol, LDL receptor expression is increased in the biledepleted liver resulting in reduced LDL-C levels. An $18 \%-$ $25 \%$ reduction in LDL-C has been observed with bile acid sequestrants, and they are primarily used to reduce LDL-C in patients intolerant to statins or in combination, where targets are not reached with statin alone. Bile acid sequestrants have been shown to reduce cardiovascular morbidity [43].

\section{Niacin}

Niacin (also known as vitamin B3 or nicotinic acid) has a broad effect on modulating lipoprotein levels (at a dosage of $2 \mathrm{~g} /$ day): it increases HDL-C by $15 \%-35 \%$ and reduces TG by $20 \%-40 \%$ and LDL-C by $15 \%-18 \%$. The effect on LDL-C and TG is primarily mediated by retention of VLDL by the liver. Niacin is used in patients with hypertriglyceridemia or combined hyperlipidemia often in combination with a statin. In clinical trials, niacin has been shown to reduce cardiovascular morbidity but not mortality [44]. Niacin is the most potent drug to increase HDL-C and at present the only drug that reduces $\mathrm{Lp}(\mathrm{a})$. The clinical significance of this, however, has not been shown. The recent failure of the AIM-HIGH [45] and the HPS-2 THRIVE [46](THRIVE home Page: www.thrivestudy.org) studies makes the future of niacin in cardiovascular prevention doubtful .

Fibrates

Fibrates (fenofibrate, gemfibrozil, clofibrate, ciprofibrate, and bezafibrate) cause a reduction in the levels of TG-rich particles, both in the fasting and in the postprandial state, due to their agonist effect on peroxisome proliferator-activated receptor (PPAR) $\alpha$. Fibrates also result in a modest increase of HDL-C. They are primarily used in individuals with hypertriglyceridemia or in high-risk patients with mixed hyperlipidemia [44]. In clinical trials fibrates have shown a reduction in the rate of non fatal myocardial infarction, however, often only in post-hoc analyses [47].

\section{Combination Therapy}

In many cases targets are not reached with the highest dose of 1 drug, or the dose has to be kept low due to side effects. In these cases combination therapy should be considered. However, the number of clinical trials showing clinical benefit from combination therapy is limited. In patients with hypercholesterolemia statin can be combined with a bile acid sequestrant or a cholesterol absorption inhibitor. In the SHARP trial the combination of simvastatin and ezetimibe was shown to reduce CVD in patients with CKD [48]. The combination of fibrate and statin has been shown to improve reduction in both LDL-C and TG. The results from clinical trials have not shown a reduction in $\mathrm{CV}$. However, in post hoc analyses from studies patients with high TG and low HDL seem to benefit from the combination of fenofibrate and a statin. Therefore the combination may be considered in certain patients at high risk [5]. In combination therapy drug interactions have to be considered. This especially refers to the interaction between statins and fibrates, since both drugs are associated with increased risk of myopathy (see below). Furthermore the combination of niacin/laropiprant and statin is associated with increased frequency of myopathy as shown in HPS2-THRIVE [46]. 


\section{How Should Lipids Be Monitored?}

Before initiation of therapy, lipids should be measured at least twice and the lipid levels evaluated as a part of global risk estimation, preferentially using 1 of the available risk calculators such as SCORE [4]. Dyslipidemia should be diagnosed with complete lipid status including (at least) TC, LDL-C, TG, and HDL-C (similar information may be obtained by non-HDL-C, apoB, and apoAI). Possible underlying metabolic disturbances and other diseases should be excluded by measuring (at least) glucose, alanine, and aspartate transaminases (ALT and AST), creatinine and thyroidstimulating hormone.

Lipids should be checked 6-8 weeks after initiation of therapy and also after any change to drug therapy, such as dose change, change of compound, or starting combination therapy. The effect of statins is seen already after 4 weeks but other drugs may take longer. A longer time-frame is required to see the effect of lifestyle changes such as diet, weight reduction, and increased physical activity. Patients who have reached therapeutic goals and are in a stable condition often only need to be checked once a year. However, more frequent controls should be considered to improve adherence to lifestyle changes and to pharmacological treatment. The importance of regular lipid monitoring has been reported in several studies [49].

The lipid parameters that are analyzed in the regular checks should be determined by the original dyslipidemia. As a minimum, T-C should be measured, but better management and probably better patient compliance are achieved if a full lipid profile (including LDL-C, HDL-C, and TG) is obtained. ApoB and non-HDL-C are alternative measures that may be used, especially in patients with hypertriglyceridemia. Non-HDL-C is a good marker for TG and TG-rich remnant particles $[5,9]$. The experience with apoB is, however, still limited in routine clinical settings.

A disadvantage of measuring a single plasma lipid at 1 occasion is that there is considerable intra-individual variation, estimated at about $7 \%$ for cholesterol and $28 \%$ for triglycerides [50]. This variation results from analytical error, individual variation due to other factors and seasonal variation, with highest levels during the summer and lowest during the winter [51]. These intra-individual variations should be taken into account, and small changes should be checked before therapy is changed.

\section{Safety Monitoring}

Statins

Statins are considered to be relatively safe drugs. The most important side effects, which should be monitored, are muscle or liver related. Side effects are dose dependent and influenced by other conditions such as: age, female gender, small body size, alcohol abuse, presence of multisystemic diseases, reduced kidney or liver function, and interaction with other drugs.

\section{Monitoring of Muscle-Related Side Effects}

Muscle symptoms are the most common and serious side effects of statins $[52,53 \bullet]$, leading to poor compliance or statin intolerance. It is essential during follow up that both the patient and the physician are aware of the possible association between muscle symptoms and statins, since the symptoms often are vague and difficult to interpret. As long as levels of the circulating muscle enzyme creatine kinase (CK) remain normal, statin therapy may continue if the symptoms are acceptable to the patient (Table 3).

Myalgia may be defined as the presence of muscle pain or tenderness without elevation of CK. The frequency of myalgia varies from $1.5 \%-5 \%$ in randomized studies $[54,55]$ to $5 \%-10 \%$ in observational studies $[56,57]$. The symptoms are most often located to bigger proximal muscle groups, but can also have other locations [53•]. They often appear within a couple of months of starting therapy or after dose adjustment. The cause of the symptoms is unclear $[53 \cdot, 58]$.

Severe myopathy (rhabdomyolysis) is characterized by severe muscular pain, with an elevation of the muscle enzymes to more than 10 times the upper limit of normal. In addition, the patient may develop myoglobinuria and, eventually, renal insufficiency. The incidence of rhabdomyolysis has been estimated to be 1-3 cases per 100,000 patient years [54]. Death occurring after rhabdomyolysis has been estimated to occur in 0.15 per million treated patients [59].

The monitoring of possible muscular side effects should be especially directed towards the risk groups. Myalgia is more common in physically active subjects. Myopathy is more common in patients with previously high CK, women, the elderly, and patients with reduced renal or liver function. The genetic background is also involved in the development of muscular symptoms since family history is a risk factor. Indeed, genetic variations in transport proteins and cytochrome P450 (CYP) enzymes have been identified as risk factors for myopathy $[53 \bullet, 58]$.

The most common cause of severe myopathy is probably interactions with other drugs. Many drugs are dependent on CYP3A4 for their catabolism, and these may thus interact with the CYP3A4-dependent statins simvastatin, lovastatin, and atorvastatin. Pravastatin, rosuvastatin, and fluvastatin are catabolized through other enzymes (CYP2C9). Statins combined with gemfibrozil are associated with increased risk of rhabdomyolysis while this risk is much smaller when statins are combined with fenofibrate or niacin. Examples of drugs that potentially interact with statins are given in Table 4. 
Table 3 Safety monitoring during treatment with lipid lowering drugs

$A L T$ alanine aminotransferase, $C K$ creatinine kinase, $U L N$ upper limit of normal

Modified from [3•].

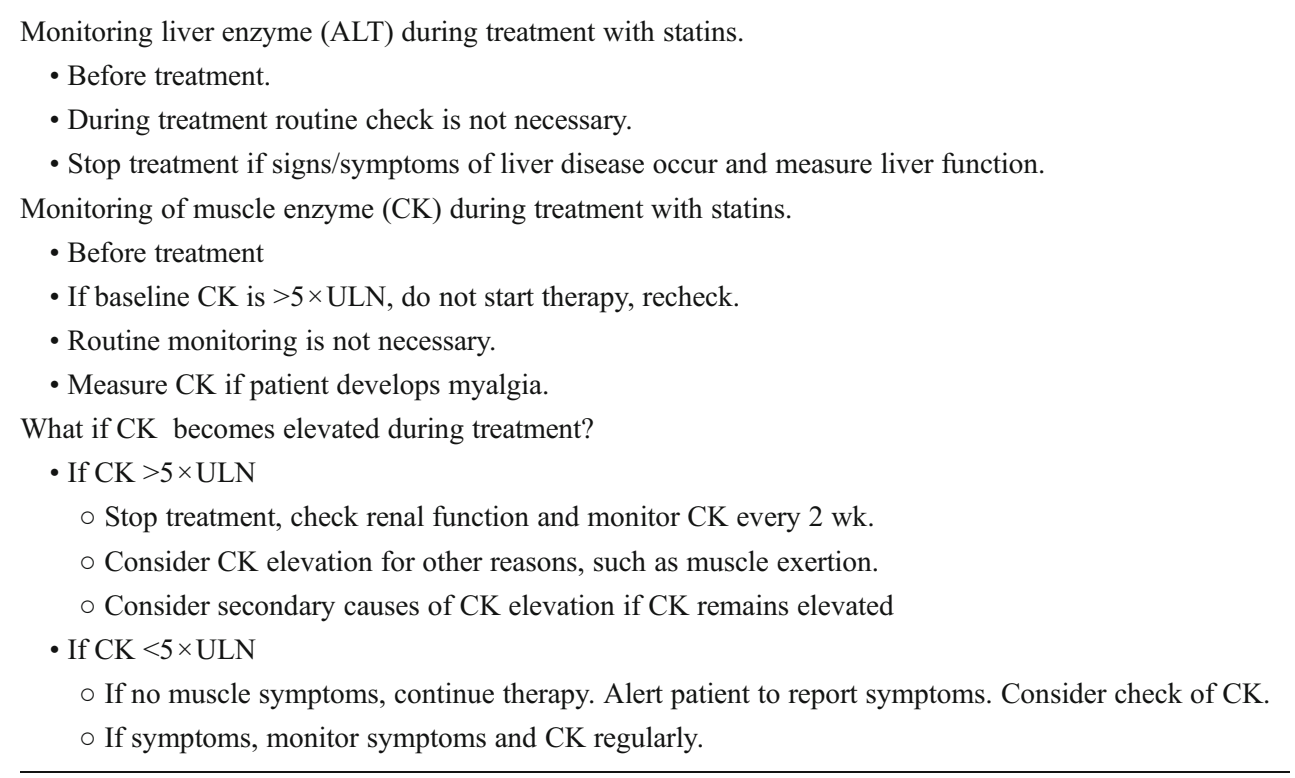

The risk for myopathy increases with dose [60]. There is no conclusive evidence that risk for myopathy varies between the statins when used at regular doses, with the exception of cerivastatin. However, the US Food and Drug Administration (FDA) recently concluded that high-dose simvastatin $(80 \mathrm{mg} / \mathrm{d})$ is associated with higher risk and should not be used; the interaction between lower doses of simvastatin and other drugs was also emphasized [61].

In addition to actively asking for symptoms, CK elevation is the most important tool to detect severe myopathy. CK should be checked before initiation of therapy; if elevated, it should be checked again and, if still elevated, the use of statins should be reconsidered. CK elevations are often seen spontaneously and can be caused by several factors such as high physical activity. Therefore, CK elevation without symptoms has a very poor specificity, and a routine check of CK is not recommended. According to current guidelines, CK should be checked if muscle symptoms appear. If CK is less than 5 times the upper limit of normal, continue statins and monitor CK. If CK is over 5 times the upper limit, stop

Table 4 Drugs that potentially interact with statins leading to increased risk of myopathy and rhabdomyolysis

\begin{tabular}{lll}
\hline Anti-infective agents & Calcium antagonists & Other \\
\hline Itraconazole & Verapamil & Cyclosporine \\
Ketoconazole & Diltiazem & Danazol \\
Posaconazole & Amlodipine & Amiodarone \\
Erythromycin & & Ranolazine \\
Clarithromycin & & Grapefruit juice \\
Telithromycin & & Nefazodone \\
HIV protease inhibitors & & Gemfibrozil \\
\hline
\end{tabular}

Modified from [61]. treatment, check renal function, and monitor CK every 2weeks (Table 3). It is also important to consider other reasons for the $\mathrm{CK}$ elevation $[3 \cdot 4]$.

\section{Monitoring of Liver Enzymes}

Treatment with statins tends to increase hepatic transaminases. This effect is dose-dependent and meta-analyses of randomized placebo controlled trials demonstrate that low to moderate doses of statins are not associated with clinically significant elevations in transaminases $(>3 \times$ ULN) $[62,63]$. Maximal doses of all statins are associated with a modest but significant elevation of transaminase levels [63, 64]. Until recently, guidelines have recommended that liver enzymes should be monitored before statin treatment and regularly during treatment [3•]. In 2006, the National Lipid Association Statin Safety Task Force published an assessment of statin safety as well as conclusions and recommendations $[65,66]$. The task force found that significant liver disease caused by statin treatment was extremely uncommon, and elevations of liver enzymes will often resolve with continued therapy. Based on this information FDA in 2012 changed the recommendation regarding control of liver enzymes during statin therapy. The new recommendation says that hepatic function test should be performed before starting therapy and as clinically indicated thereafter, not as a routine monitoring (FDA Drug Safety Communication (February 28, 2012) [67]. Special attention should be directed towards clinical symptoms in patients with increased risk for statin related side effects.

The presence of non alcoholic fatty liver disease should not be a contraindication to statin therapy [68-70]. Moderately elevated liver enzymes do not seem to be associated 
with increased risk of hepatotoxicity. There are even studies suggesting that statins may improve the liver disease [71-74].

\section{Monitoring of Diabetes}

Many patients with diabetes are treated with lipid-lowering drugs. Recent meta-analyses have shown an increased risk of developing diabetes during statin treatment $[75,76]$. The risk is higher with high-dose statins [77, 78], in older patients and in groups with known risk factors for diabetes. Statin therapy was associated with a $9 \%$ increased risk for incident diabetes. Treatment of 255 patients with statins for 4 years resulted in 1 extra case of diabetes [75]. The clinician should consider screening for diabetes in patients with risk factors for developing diabetes $[67,79,80]$.

\section{Fibrates}

Fibrates are in general well tolerated. Myopathy is reported at a similar or even somewhat higher frequency compared with statins [81]. Elevations of liver enzymes are also observed. Consequently muscular symptoms and CK should be monitored according to the same recommendations as for statins (Table 3). Regular control of ALT is still recommended during fibrate treatment. Fibrates are also reported to raise creatinine, but it is not clear whether this reflects change in kidney function. Monitoring of creatinine is recommended yearly for patients with risk factors such as type 2 diabetes or already elevated creatinine levels $[3 \cdot, 81]$. Fibrates may also increase homocysteine levels; this has not been shown to be of clinical relevance, and monitoring of homocysteine is not recommended.

\section{Niacin}

Elevated liver enzymes are also reported with niacin and should be monitored as suggested for fibrates. Niacin may increase blood glucose, which should be monitored in patients with diabetes or at risk of developing diabetes [44, 82, 83]. In combination with statin, niacin is associated with increased risk of myopathy [46], and CK should be monitored if muscle symptoms appear.

\section{Ezetimibe and Bile Acid Sequestrants}

Because the main site of action of these compounds is in the intestine, they do not require any specific monitoring in addition to their effects on plasma lipid levels [39, 84-86].
Safety Monitoring in the Elderly

The use of lipid-lowering drugs in the elderly is still a controversial issue but available data suggest that hyperlipidemia should be treated according to the general guidelines at least up to the age of 70. In a meta-analysis by the Cholesterol Treatment Trialists'(CTT) collaboration, the reduction in cardiovascular end points was significant up to age 75 years and also older, although only a few people were included [28]. There are also data supporting statin treatment in secondary prevention for patients above 80 years [87•].

The risk of side effects increases with age because of organ dysfunction (liver and kidney) and polypharmacy with the resulting increase in the potential for drug interactions $[67,88]$. Many drugs commonly used in the elderly interact through the CYP3A system, which should be considered. The doses should be adjusted and potential side effects monitored more vigorously. High age is a risk factor for severe myopathy, and clinicians should actively ask about muscular symptoms; when positive, CK should be checked. In the elderly, even minor muscle symptoms may seriously affect the quality of life. Increased ALT is a common side effect but this has not been found to be more common among the elderly.

A few case reports on cognitive disturbances in the elderly have been published [89]. At present, these reports are considered to be of minor significance and, according to the FDA, should not support any changes in the use of statins among the elderly [67].

\section{Conclusions}

Based on available risk algorithms and intervention trials, T$\mathrm{C}$ and LDL-C should be the first variables used to assess cardiovascular risk. Other risk factors include HDL-C (an important independent risk factor for cardiovascular disease), TG (an indicator of the metabolic status), and nonHDL-C and apoB (which should especially be considered in patients with hypertriglyceridemia or mixed hyperlipidemia). Other main risk factors (diabetes mellitus, smoking, hypertension etc.) should also be considered to give an overall cardiovascular risk assessment. New markers such as $\mathrm{Lp}(\mathrm{a})$ and $\mathrm{Lp}-\mathrm{PLA}_{2}$ are emerging as cardiovascular risk factors, but future studies are required to understand how to use these in clinical practice.

The primary treatment target in cardiovascular prevention is LDL-C and potential alternative targets are apoB and nonHDL-C. In selected high-risk individuals, TG should be targeted with drug treatment, but HDL-C, Lp(a), and ratios such as LDL-C/HDL-C or apoB/apoAI are not recommended as treatment targets. Lipids should be monitored during 
titration to targets and, thereafter, at least once a year or more frequently to improve treatment adherence if indicated.

Monitoring of muscle and liver enzymes should be done before the start of treatment. In stable conditions during treatment, the focus should be on clinical symptoms that may alert muscle or liver complications. Routine measurement of CK or ALT is not necessary during treatment with statins.

\section{Compliance with Ethics Guidelines}

Conflict of Interest Olov Wiklund has been a consultant for SanofiAventis; and has received honoraria from AstraZeneca, Pfizer, SanofiAventis, and Merck. Carlo Pirazzi declares that he has no conflict of interest. Stefano Romeo declares that he has no conflict of interest.

Human and Animal Rights and Informed Consent This article does not contain any studies with human or animal subjects performed by any of the authors.

Open Access This article is distributed under the terms of the Creative Commons Attribution License which permits any use, distribution, and reproduction in any medium, provided the original author(s) and the source are credited.

\section{References}

Papers of particular interest, published recently, have been highlighted as:

- Of importance

-• Of outstanding importance

1. Bjorck L, Capewell S, Bennett K, Lappas G, Rosengren A. Increasing evidence-based treatments to reduce coronary heart disease mortality in Sweden: quantifying the potential gains. J Intern Med. 2011;269:452-67.

2. Bjorck L, Rosengren A, Bennett K, Lappas G, Capewell S. Modelling the decreasing coronary heart disease mortality in Sweden between 1986 and 2002. Eur Heart J. 2009;30:1046-56.

3. - Catapano AL, Reiner Z, De Backer G, Graham I, Taskinen MR, Wiklund $\mathrm{O}$, et al. ESC/EAS Guidelines for the management of dyslipidaemias. The Task Force for the management of dyslipidaemias of the European Society of Cardiology (ESC) and the European Atherosclerosis Society (EAS). Atherosclerosis. 2011;217:3-46. These European guidelines give an updated information about the background and the treatment of dyslipidaemias in cardiovascular prevention.

4. Perk J, De Backer G, Gohlke H, Graham I, Reiner Z, Verschuren M, et al. European Guidelines on cardiovascular disease prevention in clinical practice (version 2012). The Fifth Joint Task Force of the European Society of Cardiology and Other Societies on Cardiovascular Disease Prevention in Clinical Practice (constituted by representatives of 9 societies and by invited experts). Developed with the special contribution of the European Association for Cardiovascular Prevention \& Rehabilitation (EACPR). Eur Heart J. 2012;33:1635-701.

5. Chapman MJ, Ginsberg HN, Amarenco P, Andreotti F, Boren J, Catapano AL, et al. Triglyceride-rich lipoproteins and high-density lipoprotein cholesterol in patients at high risk of cardiovascular disease: evidence and guidance for management. Eur Heart J. 2011;32:1345-61.
6. Walldius G, Jungner I, Holme I, Aastveit AH, Kolar W, Steiner E. High apolipoprotein B, low apolipoprotein A-I, and improvement in the prediction of fatal myocardial infarction (AMORIS study): a prospective study. Lancet. 2001;358:2026-33.

7. Holewijn S, den Heijer M, Swinkels DW, Stalenhoef AF, de Graaf J. Apolipoprotein B, non-HDL cholesterol and LDL cholesterol for identifying individuals at increased cardiovascular risk. J Intern Med. 2010;268:567-77.

8. Sniderman AD, Williams K, Contois JH, Monroe HM, McQueen MJ, de Graaf J, et al. A meta-analysis of low-density lipoprotein cholesterol, non-high-density lipoprotein cholesterol, and apolipoprotein B as markers of cardiovascular risk. Circ Cardiovasc Qual Outcomes. 2011;4:337-45.

9. Di Angelantonio E, Sarwar N, Perry P, Kaptoge S, Ray KK, Thompson A, et al. Major lipids, apolipoproteins, and risk of vascular disease. JAMA. 2009;302:1993-2000.

10. •- Di Angelantonio E, Gao P, Pennells L, Kaptoge S, Caslake M, Thompson A, et al. Lipid-related markers and cardiovascular disease prediction. JAMA. 2012;307:2499-506. An important analysis of the effects on risk prediction when cholesterol based lipid markers are substituted by emerging measures, or new markers are added.

11. Tognon G, Berg C, Mehlig K, Thelle D, Strandhagen E, Gustavsson $\mathrm{J}$, et al. Comparison of apolipoprotein (apoB/apoA-I) and lipoprotein (total cholesterol/HDL) ratio determinants. Focus on obesity, diet, and alcohol intake. PLoS One. 2012;7:e40878.

12. Ndumele CE, Matsushita K, Astor B, Virani SS, Mora S, Williams EK, et al. Apolipoproteins do not add prognostic information beyond lipoprotein cholesterol measures among individuals with obesity and insulin resistance syndromes: The ARIC Study. Eur J Prev Cardiol. 2012. doi:10.1177/2047487312465523.

13. Rana JS, Boekholdt SM, Kastelein JJ, Shah PK. The role of nonHDL cholesterol in risk stratification for coronary artery disease. Curr Atheroscler Rep. 2012;14:130-4.

14. SarwarN, SandhuMS, Ricketts SL, Butterworth AS, Di Angelantonio E, Boekholdt SM, et al. Triglyceride-mediated pathways and coronary disease: collaborative analysis of 101 studies. Lancet. 2010;375:1634-9.

15. Ewald N, Hardt PD, Kloer HU. Severe hypertriglyceridemia and pancreatitis: presentation and management. Curr Opin Lipidol. 2009;20:497-504.

16. Packard CJ. Small dense low-density lipoprotein and its role as an independent predictor of cardiovascular disease. Curr Opin Lipidol. 2006; $17: 412-7$

17. Kamstrup PR, Tybjærg-Hansen A, Nordestgaard BG. Extreme lipoprotein(a) levels and improved cardiovascular risk prediction. J Am Coll Cardiol. 2013;61:1146-56.

18. Nordestgaard BG, Chapman MJ, Ray K, Boren J, Andreotti F, Watts GF, et al. Lipoprotein(a) as a cardiovascular risk factor: current status. Eur Heart J. 2010;31:2844-53.

19. Kronenberg F, Utermann G. Lipoprotein(a): resurrected by genetics. J Intern Med. 2013;273:6-30.

20. Vittos O, Toana B, Vittos A, Moldoveanu E. Lipoprotein-associated phospholipase A2 (Lp-PLA2): a review of its role and significance as a cardiovascular biomarker. Biomarkers. 2012;17:289-302.

21. Hui DY. Phospholipase A(2) enzymes in metabolic and cardiovascular diseases. Curr Opin Lipidol. 2012;23:235-40.

22. Catapano AL, Chapman J, Wiklund O, Taskinen MR. The new joint EAS/ESC guidelines for the management of dyslipidaemias. Atherosclerosis. 2011;217:1.

23. Third Report of the National Cholesterol Education Program (NCEP) Expert panel on detection, evaluation, and treatment of high blood cholesterol in adults (Adult Treatment Panel III) final report. Circulation. 2002;106:3143-421.

24. Grundy SM, Cleeman JI, Merz CN, Brewer Jr HB, Clark LT, Hunninghake DB, et al. Implications of recent clinical trials for the National Cholesterol Education Program Adult Treatment Panel III guidelines. Circulation. 2004;110:227-39. 
25. JBS 2: Joint British Societies' guidelines on prevention of cardiovascular disease in clinical practice. Heart. 2005;91(Suppl 5):v1-52.

26. Genest J, McPherson R, Frohlich J, Anderson T, Campbell N, Carpentier A, et al. 2009 Canadian Cardiovascular Society/Canadian guidelines for the diagnosis and treatment of dyslipidemia and prevention of cardiovascular disease in the adult - 2009 recommendations. Can J Cardiol. 2009;25:567-79.

27. •- Mihaylova B, Emberson J, Blackwell L, Keech A, Simes J, Barnes EH, et al. The effects of lowering LDL cholesterol with statin therapy in people at low risk of vascular disease: meta-analysis of individual data from 27 randomised trials. Lancet. 2012;380:58190. An important meta-analysis showing effects of statin treatment also in patient with low risk.

28. Baigent C, Blackwell L, Emberson J, Holland LE, Reith C, Bhala $\mathrm{N}$, et al. Efficacy and safety of more intensive lowering of LDL cholesterol: a meta-analysis of data from 170,000 participants in 26 randomised trials. Lancet. 2010;376:1670-81.

29. Sniderman A, Thanassoulis G, Couture P, Williams K, Alam A, Furberg CD. Is lower and lower better and better? A re-evaluation of the evidence from the Cholesterol Treatment Trialists' Collaboration meta-analysis for low-density lipoprotein lowering. J Clin Lipidol. 2012;6:303-9.

30. Sniderman AD, De Graaf J, Couture P. Low-density lipoproteinlowering strategies: target versus maximalist versus population percentile. Curr Opin Cardiol. 2012;27:405-11.

31. Robinson JG, Wang S, Jacobson TA. Meta-analysis of comparison of effectiveness of lowering apolipoprotein B versus low-density lipoprotein cholesterol and nonhigh-density lipoprotein cholesterol for cardiovascular risk reduction in randomized trials. Am J Cardiol. 2012;110:1468-76.

32. Mora S, Wenger NK, Demicco DA, Breazna A, Boekholdt SM, Arsenault BJ, et al. Determinants of residual risk in secondary prevention patients treated with high- versus low-dose statin therapy: the Treating to New Targets (TNT) study. Circulation. 2012;125:1979-87.

33. Boekholdt SM, Arsenault BJ, Mora S, Pedersen TR, LaRosa JC, Nestel PJ, et al. Association of LDL cholesterol, non-HDL cholesterol, and apolipoprotein B levels with risk of cardiovascular events among patients treated with statins: a meta-analysis. JAMA. 2012;307:1302-9.

34. Mora S, Glynn RJ, Boekholdt SM, Nordestgaard BG, Kastelein JJ, Ridker PM. On-treatment non-high-density lipoprotein cholesterol, apolipoprotein $\mathrm{B}$, triglycerides, and lipid ratios in relation to residual vascular risk after treatment with potent statin therapy: JUPITER (justification for the use of statins in prevention: an intervention trial evaluating rosuvastatin). J Am Coll Cardiol. 2012;59:1521-8.

35. Barter PJ, Caulfield M, Eriksson M, Grundy SM, Kastelein JJ, Komajda M, et al. Effects of torcetrapib in patients at high risk for coronary events. N Engl J Med. 2007;357:2109-22.

36. Schwartz GG, Olsson AG, Abt M, Ballantyne CM, Barter PJ, Brumm J, et al. Effects of dalcetrapib in patients with a recent acute coronary syndrome. N Engl J Med. 2012;367:2089-99.

37. Voight BF, Peloso GM, Orho-Melander M, Frikke-Schmidt R, Barbalic $\mathrm{M}$, Jensen MK, et al. Plasma HDL cholesterol and risk of myocardial infarction: a mendelian randomisation study. Lancet. 2012;380:572-80.

38. Weng TC, Yang YH, Lin SJ, Tai SH. A systematic review and metaanalysis on the therapeutic equivalence of statins. J Clin Pharm Ther. 2010;35:139-51.

39. Phan BA, Dayspring TD, Toth PP. Ezetimibe therapy: mechanism of action and clinical update. Vasc Health Risk Manag. 2012;8:415-27.

40. Suchy D, Labuzek K, Stadnicki A, Okopien B. Ezetimibe-a new approach in hypercholesterolemia management. Pharmacol Rep. 2011;63:1335-48

41. Descamps OS, De Sutter J, Guillaume M, Missault L. Where does the interplay between cholesterol absorption and synthesis in the context of statin and/or ezetimibe treatment stand today? Atherosclerosis. 2011;217:308-21.
42. Cannon CP, Giugliano RP, Blazing MA, Harrington RA, Peterson JL, Sisk CM, et al. Rationale and design of IMPROVE-IT (IMProved Reduction of Outcomes: Vytorin Efficacy International Trial): comparison of ezetimbe/simvastatin versus simvastatin monotherapy on cardiovascular outcomes in patients with acute coronary syndromes. Am Heart J. 2008;156:826-32.

43. Tyroler HA. Cholesterol and cardiovascular disease. An overview of Lipid Research Clinics (LRC) epidemiologic studies as background for the LRC Coronary Primary Prevention Trial. Am J Cardiol. 1984;54:14C-9C.

44. Chapman MJ, Redfern JS, McGovern ME, Giral P. Niacin and fibrates in atherogenic dyslipidemia: pharmacotherapy to reduce cardiovascular risk. Pharmacol Ther. 2010;126:314-45.

45. Boden WE, Probstfield JL, Anderson T, Chaitman BR, DesvignesNickens P, Koprowicz K, et al. Niacin in patients with low HDL cholesterol levels receiving intensive statin therapy. N Engl J Med. 2011;365:2255-67.

46. Group H-TC. HPS2-THRIVE randomized placebo-controlled trial in 25,673 high-risk patients of ER niacin/laropiprant: trial design, pre-specified muscle and liver outcomes, and reasons for stopping study treatment. Eur Heart J. 2013;34:1279-91.

47. Romeo S, Huang-Doran I, Baroni MG, Kotronen A. Unravelling the pathogenesis of fatty liver disease: patatin-like phospholipase domain-containing 3 protein. Curr Opin Lipidol. 2010;21:247-52.

48. Baigent C, Landray MJ, Reith C, Emberson J, Wheeler DC, Tomson $\mathrm{C}$, et al. The effects of lowering LDL cholesterol with simvastatin plus ezetimibe in patients with chronic kidney disease (Study of Heart and Renal Protection): a randomized placebocontrolled trial. Lancet. 2011;377:2181-92.

49. Coodley GO, Jorgensen M, Kirschenbaum J, Sparks C, Zeigler L, Albertson BD. Lowering LDL cholesterol in adults: a prospective, community-based practice initiative. Am J Med. 2008;121:604-10.

50. Nazir DJ, Roberts RS, Hill SA, McQueen MJ. Monthly intraindividual variation in lipids over a 1-year period in 22 normal subjects. Clin Biochem. 1999;32:381-9.

51. Ockene IS, Chiriboga DE, Stanek III EJ, Harmatz MG, Nicolosi R, Saperia G, et al. Seasonal variation in serum cholesterol levels: treatment implications and possible mechanisms. Arch Intern Med. 2004;164:863-70.

52. Pasternak RC, Smith Jr SC, Bairey-Merz CN, Grundy SM, Cleeman JI, Lenfant C. ACC/AHA/NHLBI clinical advisory on the use and safety of statins. J Am Coll Cardiol. 2002;40:567-72.

53. - Abd TT, Jacobson TA. Statin-induced myopathy: a review and update. Expert Opin Drug Saf. 2011;10:373-87. This review and update summarizes the most recent studies on statins and myopathy.

54. Law M, Rudnicka AR. Statin safety: a systematic review. Am J Cardiol. 2006;97:52C-60C.

55. Silva MA, Swanson AC, Gandhi PJ, Tataronis GR. Statin-related adverse events: a meta-analysis. Clin Ther. 2006;28:26-35.

56. Davidson MH, Clark JA, Glass LM, Kanumalla A. Statin safety: an appraisal from the adverse event reporting system. Am J Cardiol. 2006;97:32C-43C

57. Bruckert E, Hayem G, Dejager S, Yau C, Begaud B. Mild to moderate muscular symptoms with high-dosage statin therapy in hyperlipidemic patients-the PRIMO study. Cardiovasc Drugs Ther. 2005;19:403-14.

58. Arca M, Pigna G. Treating statin-intolerant patients. Diabetes Metab Syndr Obes. 2011;4:155-66.

59. Kashani A, Phillips CO, Foody JM, Wang Y, Mangalmurti S, Ko DT, et al. Risks associated with statin therapy: a systematic overview of randomized clinical trials. Circulation. 2006;114:2788-97.

60. Silva M, Matthews ML, Jarvis C, Nolan NM, Belliveau P, Malloy $\mathrm{M}$, et al. Meta-analysis of drug-induced adverse events associated with intensive-dose statin therapy. Clin Ther. 2007;29:253-60.

61. Egan A, Colman E. Weighing the benefits of high-dose simvastatin against the risk of myopathy. N Engl J Med. 2011;365:285-7. 
62. de Denus S, Spinler SA, Miller K, Peterson AM. Statins and liver toxicity: a meta-analysis. Pharmacotherapy. 2004;24:584-91.

63. Wlodarczyk J, Sullivan D, Smith M. Comparison of benefits and risks of rosuvastatin versus atorvastatin from a meta-analysis of head-tohead randomized controlled trials. Am J Cardiol. 2008;102:1654-62.

64. Bradford RH, Shear CL, Chremos AN, Dujovne CA, Franklin FA, Grillo RB, et al. Expanded Clinical Evaluation of Lovastatin (EXCEL) study results: 2-year efficacy and safety follow-up. Am J Cardiol. 1994;74:667-73.

65. Cohen DE, Anania FA, Chalasani N. An assessment of statin safety by hepatologists. Am J Cardiol. 2006;97:77C-81C.

66. McKenney JM, Davidson MH, Jacobson TA, Guyton JR. Final conclusions and recommendations of the National Lipid Association Statin Safety Assessment Task Force. Am J Cardiol. 2006;97:89C-94C.

67. Marcum ZA, Vande Griend JP, Linnebur SA. FDA drug safety communications: a narrative review and clinical considerations for older adults. Am J Geriatr Pharmacother. 2012;10:264-71.

68. Vuppalanchi R, Teal E, Chalasani N. Patients with elevated baseline liver enzymes do not have higher frequency of hepatotoxicity from lovastatin than those with normal baseline liver enzymes. Am J Med Sci. 2005;329:62-5.

69. Chalasani N, Aljadhey H, Kesterson J, Murray MD, Hall SD. Patients with elevated liver enzymes are not at higher risk for statin hepatotoxicity. Gastroenterology. 2004;126:1287-92.

70. Gillett Jr RC, Norrell A. Considerations for safe use of statins: liver enzyme abnormalities and muscle toxicitiy. Am Fam Physician. 2011;83:711-6.

71. Rallidis LS, Drakoulis CK, Parasi AS. Pravastatin in patients with nonalcoholic steatohepatitis: results of a pilot study. Atherosclerosis. 2004;174:193-6.

72. Han KH, Rha SW, Kang HJ, Bae JW, Choi BJ, Choi SY, et al. Evaluation of short-term safety and efficacy of HMG-CoA reductase inhibitors in hypercholesterolemic patients with elevated serum alanine transaminase concentrations: PITCH study (PITavastatin versus atorvastatin to evaluate the effect on patients with hypercholesterolemia and mild to moderate hepatic damage). J Clin Lipidol. 2012;6:340-51.

73. Nseir W, Mograbi J, Ghali M. Lipid-lowering agents in nonalcoholic fatty liver disease and steatohepatitis: human studies. Dig Dis Sci. 2012;57:1773-81.

74. Wierzbicki AS, Oben J. Nonalcoholic fatty liver disease and lipids. Curr Opin Lipidol. 2012;23:345-52.

75. Sattar N, Preiss D, Murray HM, Welsh P, Buckley BM, de Craen AJ, et al. Statins and risk of incident diabetes: a collaborative metaanalysis of randomised statin trials. Lancet. 2010;375:735-42.
76. Rajpathak SN, Kumbhani DJ, Crandall J, Barzilai N, Alderman M, Ridker PM. Statin therapy and risk of developing type 2 diabetes: a meta-analysis. Diabetes Care. 2009;32:1924-9.

77. Preiss D, Sattar N. Statins and the risk of new-onset diabetes: a review of recent evidence. Curr Opin Lipidol. 2011;22:460-6.

78. Waters DD, Ho JE, Boekholdt SM, DeMicco DA, Kastelein JJ, Messig M, et al. Cardiovascular event reduction versus new-onset diabetes during atorvastatin therapy: effect of baseline risk factors for diabetes. J Am Coll Cardiol. 2013;61:148-52.

79. Shah RV, Goldfine AB. Statins and risk of new-onset diabetes mellitus. Circulation. 2012;126:e282-4.

80. Goldfine AB. Statins: is it really time to reassess benefits and risks? N Engl J Med. 2012;366:1752-5.

81. Davidson MH, Armani A, McKenney JM, Jacobson TA. Safety considerations with fibrate therapy. Am J Cardiol. 2007;99:3C$18 \mathrm{C}$.

82. Guyton JR. Niacin in cardiovascular prevention: mechanisms, efficacy, and safety. Curr Opin Lipidol. 2007;18:415-20.

83. Guyton JR, Bays HE. Safety considerations with niacin therapy. Am J Cardiol. 2007;99:22C-31C.

84. Morrone D, Weintraub WS, Toth PP, Hanson ME, Lowe RS, Lin J, et al. Lipid-altering efficacy of ezetimibe plus statin and statin monotherapy and identification of factors associated with treatment response: a pooled analysis of over 21,000 subjects from 27 clinical trials. Atherosclerosis. 2012;223:251-61.

85. Davidson MH, Donovan JM, Misir S, Jones MR. A 50-week extension study on the safety and efficacy of colesevelam in adults with primary hypercholesterolemia. Am J Cardiovasc Drugs. 2010;10:305-14.

86. Florentin M, Liberopoulos EN, Mikhailidis DP, Elisaf MS. Colesevelam hydrochloride in clinical practice: a new approach in the treatment of hypercholesterolaemia. Curr Med Res Opin. 2008;24:995-1009.

87. • Gransbo K, Melander O, Wallentin L, Lindback J, Stenestrand U, Carlsson $\mathrm{J}$, et al. Cardiovascular and cancer mortality in very elderly post-myocardial infarction patients receiving statin treatment. J Am Coll Cardiol. 2010;55:1362-9. This study gives unique information about outcome of the very elderly during statin treatment after myocartdial infarction.

88. Walker DB, Jacobson TA. Initiating statins in the elderly: the evolving challenge. Curr Opin Endocrinol Diabetes Obes. 2008;15:182-7.

89. Wagstaff LR, Mitton MW, Arvik BM, Doraiswamy PM. Statinassociated memory loss: analysis of 60 case reports and review of the literature. Pharmacotherapy. 2003;23:871-80. 